\title{
Gagged Narratives from the Margin: Indian Films and the Shady Representation of Caste
}

\author{
Dr. Preeti Oza \\ St. Andrew"s College \\ University of Mumbai
}

\begin{abstract}
Popular Hindi cinema provides a fascinating account of Indian life history and cultural politics. Hindi cinema is always a mirror of the Indian society but films also have fascinated entertained the Indian public for more than a hundred years and sometimes when we analyze the history of Indian cinema we can get an amazingly interesting but actual history of the contemporary society with all its virtues and vices in different colors. This paper deliberates on the various issues pertaining to the portrayal of specific caste, especially the Dalits in Indian films- both Hindi and regional.
\end{abstract}

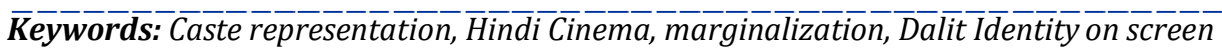

INTRODUCTION

The motion-picture medium has an extraordinary range of expression. It has in common with the plastic arts the fact that it is a visual composition projected on a two-dimensional surface; with dance, that it can deal in the arrangement of movement; with theatre, that it can create a dramatic intensity of events; with music, that it can compose in the rhythms and phrases of time and can be attended by song and instrument; with poetry, that it can juxtapose images; with literature generally, that it can encompass in its soundtrack the abstractions available only to language. (Gibson 2011)

Hindi cinema is the largest film industry in the world with the most prolific rate of production- a staggering 800 films- screen for approximately 15 million people a day. It is the dominant cultural Institution and product in India, providing multiple entertainment opportunities to the audience is drawn primarily from the working class or upper middle class in urban centers. Hindi is regional Northern language Hindi Cinemas audience transient"s language region or religious boundaries within the nation, making it fit the national cinema binding like no other.

Any critical innovation always paves way for the repercussions and sometimes they are unforeseen. Introduction of films in India during the time of Bruisers was one such incident which has set off a rippling effect. The Britishers introduced the films in India, and Indians took to it in a big time. The society which was already facing discrimination based on caste and so many other religious issues, film screening theatres served as a common ground. It was the film theatres which were earlier doubled as drama theatres also, we are one of the few places or the public places where people did not experience the discrimination based on caste.

Since its birth, cinema has attracted the attention of the poets, writers, and critics of art. The poet Blaise Cendars produced his „alphabet" of cinema, while Ricciotto Canudo, in his „Reflections on the Seventh Art”, claimed that cinema was „renewing writing", harking back to the language in images (Marcus 2012)

With the struggle of many people, the nation has progressed at a slow but steady pace in films. Apart from this, the portrayal of Dalits in Hindi cinema can be traced is an extension of the development of the elite and marginal literature in India. Movies play a significant role in the social-emotional development of an emerging adult, especially in a country like India where the larger than life portrayal of Hindi movie world is a very big part of growing up in last so many generations. Life lessons, character connections and social relationship of a movie or what stick in the mind of the audience for a very long time. Movies not only have a positive effect but might also produce a negative effect on a collective self-image of society. Finally for the movie offers for its audience are highly dependent upon the attitude of the audience in particular and the society in general. In this case, the effects of films are so overwhelming that, most countries around the world sea mass media as a tool that either disrupts the society or shapes the society.

Films play an inevitable role in creating Expectations of reality for people who regularly consume it. People who watch more drama melodrama or any other fantasies set the standard for their real-life Expectations for them. Cinema creates a potential for emotionally and curd criticism along with an ideal life of the world outside. Fictional films activate the ability to reflect and experience the meaning of being a human princess many purposes other than entertainment provided meaning in operational providing an awe of Wonder and deep understanding of the purpose of life. 


\section{GAP GYAN -}

\section{An International Peer-Reviewed \\ Open Access Journal of Social Sciences}

When it comes to the portrayal of delete or the lower castes in Indian films, it must be handled very cautiously the degrading treatment of blacks in America which can be related here in the case of Dalits in India has provided a very good case study for this. The research conducted by Teahan and Podany (1974), shows that films, which depict the blacks as successful, have a different impact on higher and lower socio-economic black youth full stop the black Sapphire social economic standard reacted more positively towards white but it was opposite for blacks of the lower social economic standard. If crying about erase increased, we just generally might result in a negative attitude towards whites the anti-white attitude might be temporary and might be in the initial step towards the improvement of the positive self-concept of Blacks.

In a similar way, it can be equated to the Dalits in the Indian scenario. When films about Dalits are comparable to the upper and middle-class general public in India, the reactions are completely different. Representation of Delhi thin film becomes a problem if non- Dalit filmmakers are involved, in spite of the good intentions. There are raising the problem of political correctness and authenticity of authority. The lips are generally portrayed as a victim or as a helpless person who represents an opportunity for the protagonist to display his heroism. Most of the time delete narratives contain victimization of the leaf and their stereotyping but what about the cinematic codes which lead fir misinterpretation of meaning! From Aachhut Kanya and Ankur to Sairat and Dhadak, the Indian Film Industry has very scarcely introduced the controversial issue of caste biases and the representation of Dalits or the lower castes directly on the Indian screens have always been meager.

In the history of more than hundred years of Hindi cinema, many filmmakers have very consciously kept away from the issue of Dalits or untouchables or any other lower castes. Of course, there are some parallel cinema movements or what we called the art cinema, which is largely inspired by the left or Marxist school of thought, have portrait delete characters as heroes and heroines in their films but it is a very rare kind of a cinema.

sometimes back the English newspaper The Hindu at published a report on Hindi cinema and delete representation according to this report in the Hindi film industry so-called progressive secular films are called the mainstream films and between 2013 to 2014300 films were made but only five of them had to delete heroes and heroines as the main protagonist. Another report published by Birmingham City University the United Kingdom in 2017 raised a very valid question regarding the representation of backward classes in the Indian Film Industry and they have identified that the share of the Dalit population is in India is more than half of the total population but their representation in the film is only $0.1 \%$.

Caste and its representation is always a very sensitive issue in Indian society for the first time the issue of caste was raised in the film called Achhut Kanya (1936) there are some instances where the Indian film directors have touched upon this subject but not on a full-fledged narrative or at the plot level there are hardly any film portrayal of the mainstream actor and actress having a role of Dalits protagonist. Achhut Kanya who was a film produced by the Bombay Talkies and it was a brave attempt to show a contemporary love story of upper caste man and lower caste women. Do the men and women cannot get married to each other in this film; it beautifully depicts the problems of marriages that take place as an arranged one without the consent of the boy or a girl. There was a very touchy narrative of untouchability running throughout this film and the director has used mob violence to show the kind of pressure which comes on the protagonist which can stop him from loving or marrying a lower caste girl to maintain his upbeat morality.

One more such attempt was done by the director Bimal Roy in his film Sujata in 1959. It is a story of an orphaned untouchable girl who is raised by Brahmin parents but they are not completely accepting her as their own daughter due to her lower berth. Sujata has to struggle very hard to attain her parents" love and she wanted to be completely accepted as their daughter. She falls in love with a young Brahmin man, who is actually supposed to get married to her stepsister, finally falls in love with Sujata, even after knowing her cast of birth. Bimal Roy beautifully portrays the character of Adhir, that young man who has to bear the burden of being the only representative of the progressive forces in the society and working against them the inhuman tradition of untouchability.

Ankur in 1974, the film by Shyam Benegal has portrait Shabana Azmi playing a lower caste woman upper caste landlord falls for. But finally Lakshmi, the main protagonist played by Shabana Azmi, has to succumb to her low-caste aspirations. 


\section{GAP GYAN -}

\section{An International Peer-Reviewed \\ Open Access Journal of Social Sciences}

In 1981 Satyajit Ray directed telefilm called Satgati, which was about a poor Dalit boy played by Om Puri, who turns around the injustice against lower castes in his village this film is interesting Lee based on a short story of Munshi Premchand on the same name.

Bawandar, a film by Jagmohan Mundra, is a true story based film of a woman who fought against all odds and emerged victoriously. In a small village of Rajasthan, Saanvari, an untouchable, was gang-raped by upper caste people for her involvement as Saathin - a helper, in an awareness campaign to eradicate the tradition of child marriage. The villagers, mainly from the upper caste Gujjar community, severally beat her and raped her in front of her husband. It was a very controversial case of that time and a unique portrayal of a fact that several members of one family raped a woman of lower caste. The Court of Law, while delivering the judgment mentioned that one cannot commit such crime in front of their family members and acquitted them. It was a shameful verdict for not only Sanwari Devi but the entire womanhood and the lower caste community

\section{GLORIFYING CASTE}

Many Hindi Films have taken it up to them to correct the collective wrong of the society by portraying the Dalit hero/ heroine in a larger than life portrayal. Glorification of one"s self, and holding them higher than their counterparts, have always existed in the Indian society. These glorifications have also seeped into the films that are made. This „Holier-than-thou" mentality of one"s caste in movies is symbolized by various aspects, such as display of power (both societal power and physical power), using symbolism of political leaders in the backgrounds, and associating with powerful animals, presenting shots which portray a larger than life image of the hero, usage of dialogues that stir audience at an emotional level etc.

Recently Marathi films have started discussing the caste issue very boldly on screen. Director Nagraj Manjule has challenged this notion of „upper caste films" with two movies Fandry(2013) and Sairat (2016) which focus on love stories with caste discrimination. Also, through his movies, he has tried to show how economic liberalization has affected the caste. Economic liberalization has allowed everyone to dream; reality, however, is far different: it is bitter. In a capitalist society everything seems possible and beautiful but, in feudal plus capitalistic society, the reality is frightening and complex. Manjule has successfully captured this conflict. Hence his movies are important in the history of Marathi movies, particularly in the context of caste. ( Kamble 2018)

"Our world is shown as colorless and poverty-stricken. Yes, we are economically poor but not culturally so. Where is the depiction of our vibrant culture, music, and food? Why is our world shown bereft of it all?" asks Kaala director Pa Ranjith. Ranjith has honed his politics to assert his Dalit identity through the cinema he makes. In Kabali (2016), for instance, the hero plays the leader of a gang of Tamilians in Malaysia. It tells the story of Tamil Dalits who were taken to Malaysia by the British as indentured labor. His film Kaala is set in Dharavi, a settlement once dominated by Tamil Dalits. As Kaala, the hero plays a leader of slumdwellers, who challenges the relentless displacement of the poor in a metropolis. The film has a generous use of Dalit symbolism. Kaala"s jeep number, MH 01 BR 1956, a reference to the year Dr. Ambedkar led the mass conversion of Dalits to Buddhism; or the blue that dominates the slums in the form of cloth, drums, tarpaulin sheets. The film "s teaser begins with the chant of "Poraduvom (We will fight)" and ends with the Ambedkarite exhortation, "Kattravai, pattravai (educate, agitate)".

(://indianexpress.com/article/express-Sunday-eye/when-Dalit-filmmakers-embrace-their- identity-andreclaim-their-stories-5209972/)

To the filmmaker, the symbolism is secondary; it"s the assertion that forms a crucial part of his cinema. "There have been films in the past that depict Dalit characters and lives. They were made by non-Dalits, who view us through a lens of pity. Our world is shown as colorless and poverty-stricken. Yes, we are economically poor but not culturally so. Where is the depiction of our vibrant culture, music, and food? Why is our world shown bereft of it all?" he says.

Most films that address caste confirm Ranjith"s analysis. They depict Dalits in minor roles of poverty and helplessness. One of the Hindi film industry"s biggest commercial successes, Lagaan (2001), for example, celebrates this kind of token "inclusion". While the rest of the village"s makeshift cricket team shuns the "untouchable" Kachra, Aamir Khan"s Bhuvan embraces the crippled man and deigns to include him in the team as a spinner.

"I understand that films such as Jabbar Patel"s Mukta (1994, about an upper-caste woman who falls in love with a Dalit activist) are well-intentioned. But why do these films have to adopt a patronizing tone?" asks Marathi filmmaker Nagraj Manjule, whose films Fandry (2013) and Sairat (2016) broke new ground in the depiction of caste relations. Sairat, a love story with Dalit actors in the lead, broke several box-office records to enter the elite Rs 100-crore club usually reserved for films by the Khans. (https://www.thequint.com/entertainment/indian-cinema/pa-ranjith-on-kaala-dalit-dravidian- politicsmajid-majidi) 


\section{GAP GYAN -}

When filmmakers from the so-called "lower" castes tell their stories, they not only aim to correct the nearerasure of their history and existence from popular culture; but they also wish to tell stories from the inside, which humanize the life of Dalits and depict it in all its complexity. Take, for instance, Neeraj Ghaywan"s Masaan, where one of the six principal characters belonged to the Dom community of Varanasi that is designated to handle and burn corpses. Played by Vicky Kaushal, Deepak"s is essentially a love story. "But one is able to sense Deepak"s aspiration, a thread that is common in the depiction of all low-caste characters in movies by Dalit filmmakers," says Waghmare. "One can see it in Manjule"s films. Be it little Jabya of Fandry or Parshya in Sairat," he says.

(https://www.vice.com/en_in/article/neqybm/somnath-waghmare-wants-to-revolutionise-dalit- cinema) Present day Indian society is marked with the rising interest of the masses and the global audience in films based on communal violence ranging from partition to the communal carnage in Gujarat during Feb. 2002. There has been a rise in the creation of films and novels dealing with the different aspects of communal violence from perspectives. The comparative study of the literary and the corresponding cinematic texts demands an in-depth understanding of the subtle aspects of cinema as an art form, the analogous formative elements of literature and cinema and the nuances of cinematic translations of literary texts.

When Somnath Waghmare, a contemporary filmmaker and a researcher, was asked about the future of Dalit representation and the "core tenet of Dalit Cinema" in the Hindi films, He said: "We have to develop an aesthetic. We will challenge the existing aesthetics. There is a stereotype that Dalits are not intellectuals or that they don"t look beautiful. [Roshmitha Harimurthy] won Miss Diva India Universe 2016, Tina Dabi topped the UPSC exams. We need to bring forward such stories. First, it will be made by people from the Dalit community. Second, its base will be constitutional values: Liberty, equality, fraternity or Buddhist values. And it will talk of assertion. It will discuss the problems we face. But it will also be about a new society."

\section{REFERENCES:}

//indianexpress.com/article/express-sunday-eye/when-dalit-filmmakers-embrace-theirreclaim-their-stories-5209972/

Dhaliwal, N. (2010, December 10).The Guardian

Gibson, Christine Mary. Cinematic Techniques in the Prose Fiction of Beatriz Guido. Diss. 1974. USA: Dissertation.com: 2001. Google Book Search. Web. 10 Jan. 2011.

http://shodhganga.inflibnet.ac.in/bitstream/10603/142786/9/09_chapter03.pdf

https://www.reuters.com/article/sairat-nagraj-manjule/qa-sairat-director-nagraj-manjule- on-the-duplicityof-indians-on-love-idUSKBN1HX18U

Kamble Ashwini, Caste and Cinema: Study of Marathi Cinema with special reference to 'Sairat' and 'Fandry', Academia.edu, 2018

Manjule, N. (2016, March 06). Discrimination exists everywhere in India. (A. Sahani, Interviewer)

Marcus, Laura. The Tenth Muse: Writing about Cinema in the Modernist Period. New York: Oxford U P, 2007. Google Book Search. Web. 10 Jan. 2012.

https://www.vice.com/en_in/article/neqybm/somnath-waghmare-wants-to-revolutionise- dalit-cinema https://www.thequint.com/entertainment/indian-cinema/pa-ranjith-on-kaala-dalit- dravidian-politics-majidmajidi 